\title{
Study on the Effect of High-Temperature Heat Treatment on the Microscopic Pore Structure and Mechanical Properties of Tight Sandstone
}

\author{
Liangbin Dou $\mathbb{D},{ }^{1,2,3}$ Guanli Shu $\mathbb{D}^{4,5}$ Hui Gao $\mathbb{D}^{1,2}$ Jinqing Bao $\mathbb{D}^{1,},{ }^{1,2}$ and Rui Wang $\mathbb{D}^{1,2}$ \\ ${ }^{1}$ School of Petroleum Engineering, Xi'an Shiyou University, Xi'an 710065, China \\ ${ }^{2}$ Key Laboratory of Unconventional Oil \& Gas Development (China University of Petroleum (East China)), Ministry of Education, \\ Qingdao 266580, China \\ ${ }^{3}$ Engineering Research Center of Development and Management for Low to Ultra-Low Permeability Oil \& Gas Reservoirs in \\ West China, Ministry of Education, Xi'an 710065, China \\ ${ }^{4}$ Department of Polymer Science and Engineering and State Key Laboratory of Metal Matrix Composites, Shanghai Jiao \\ Tong University, 800 Dongchuan Road, Shanghai 200240, China \\ ${ }^{5}$ Xinjiang Keli New Technology Development Co., Ltd., 138 Youyi Road, Karamay, 834000 Xinjiang, China
}

Correspondence should be addressed to Liangbin Dou; 77129dou@163.com and Guanli Shu; shugl824@gmail.com

Received 14 August 2020; Revised 13 October 2020; Accepted 15 March 2021; Published 5 April 2021

Academic Editor: Paolo Madonia

Copyright ( 2021 Liangbin Dou et al. This is an open access article distributed under the Creative Commons Attribution License, which permits unrestricted use, distribution, and reproduction in any medium, provided the original work is properly cited.

\begin{abstract}
The investigation of changes in physical properties, mechanical properties, and microscopic pore structure characteristics of tight sandstone after high-temperature heat treatment provides a theoretical basis for plugging removal and stimulation techniques, such as high energy gas fracturing and explosive fracturing. In this study, core samples, taken from tight sandstone reservoirs of the Yanchang Formation in the Ordos Basin, were first heated to different temperatures $\left(25-800^{\circ} \mathrm{C}\right)$ and then cooled separately by two distinct cooling methods-synthetic formation water cooling and natural cooling. The variations of wave velocity, permeability, tensile strength, uniaxial compressive strength, and microscopic pore structure of the core samples were analyzed. Experimental results demonstrate that, with the rise of heat treatment temperature, the wave velocity and tensile strength of tight sandstone decrease nonlinearly, yet its permeability increases nonlinearly. The tight sandstone's peak strength and elastic modulus exhibit a trend of the first climbing and then declining sharply with increasing temperature. After being treated by heat at different temperatures, the number of small pores varies little, but the number of large pores increases obviously. Compared to natural cooling, the values of physical and mechanical properties of core samples treated by synthetic formation water cooling are apparently smaller, whereas the size and number of pores are greater. It can be explained that water cooling brings about a dramatic reduction of tight sandstone's surface temperature, generating additional thermal stress and intensifying internal damage to the core. For different cooling methods, the higher the core temperature before cooling, the greater the thermal stress and the degree of damage caused during the cooling process. By taking into consideration of changes in physical properties, mechanical properties, and microscopic pore structure characteristics, the threshold temperature of tight sandstone is estimated in the range of $400-600^{\circ} \mathrm{C}$.
\end{abstract}

\section{Introduction}

With the further exploitation of oilfields, coal mines, and geothermal energy and the increasing operations under the deep geological conditions, the research on change in rock properties after high-temperature heat treatment attracts great attention [1]. While drilling in deep and hightemperature reservoirs, the surrounding rock of the wellbore is subject to a rapid temperature decrease after contacting with drilling fluid and mechanical properties of the rock alter, resulting in a favorable condition for breaking the rock but undermining the stability of surrounding rock. In the course 
of hydraulic fracturing in high-temperature reservoirs, there is a significant temperature difference between reservoir rock and fracturing fluid. In this case, the mechanism of fracturing involves both thermal fracturing and hydraulic pressure. During the long-term extraction of geothermal energy, the rock temperature gradually declines with the injection of circulation water. Under the combined actions of in situ stress, thermal stress, and hydraulic pressure, the reservoir rock may rupture twice or more times, further enhancing reservoir permeability and heat exchange efficiency. Moreover, as the development techniques advance, the phenomenon that the formation is first heated up and then cooled down in a quick manner takes place in the processes of the combined perforation and hydraulic fracturing and the high energy gas fracturing and plugging removal followed by water injection. For this reason, it is of great importance to study the changes in pores and permeability of hightemperature rock after water cooling [2].

Sandstone is one of the most common types of sedimentary rock and has been widely used in geological engineering research, such as the evolution of the earth's crust, oil and gas migration and accumulation, geological $\mathrm{CO}_{2}$ storage, geothermal exploitation, and nuclear waste storage [3]. Many scholars [4-21] studied the physical and mechanical properties of sandstone under high temperatures. Of those studies, experiments for the investigation of mechanical properties of the rock under thermal treatment included the compression test under and after high temperature, the tensile test under and after high temperature, creep test under high temperature, and wave velocity measurements of the rock before and after high temperature; constitutive models were established for investigating the transient mechanical properties of the rock under and after high temperature; numerical simulations were performed for the understanding of the rock's thermodynamic properties under high temperature [22]. Specifically, those studies evaluated the changes in elastic modulus, uniaxial and triaxial compressive strength, tensile strength, deformation characteristics, wave velocity, and permeability of the sandstone after thermal treatment.

However, it is noted that the research on tight sandstone is lacking as compared with that on conventional sandstone. Tight sandstone reservoir is the key area of unconventional resource development in the world $[23,24]$. Due to the complex mineral components and diverse depositional environments, tight sandstones have various pore types and intricate fractures, joints, and bedding planes. In the course of high-temperature heat treatment or cooling of tight sandstone, physicochemical changes occur to some extent, giving rise to a dramatic change in the internal structure of the sandstone and sophisticating its physical and mechanical properties [25]. Another point that lacks discussion is the effect of high-temperature heat treatment on the microscopic pore structure characteristics of tight sandstone. The influencing mechanism of thermal treatment on the microscopic pore structure and the corresponding mechanisms of plugging removal and stimulation are vital for the selection and optimization of techniques, such as high energy gas fracturing, explosive fracturing, and unconventional air oxidation thermal cracking.
In this work, the authors adopt tight sandstones taken from tight sandstone reservoirs of the Yanchang Formation in the Ordos Basin and investigate the variations of physical and mechanical properties of tight sandstone after heat treatment, especially the change in the microscopic pore structure characteristics. Additionally, the changes and evolution characteristics of microscopic structures at different scales are identified with different cooling methods and at various temperatures, aiming at providing a theoretical basis for the high energy gas or explosive fracturing and the combined perforation and hydraulic fracturing technique in tight sandstone reservoirs.

\section{Experimental Section}

2.1. Core Samples. The core samples used in the experiments were taken from tight sandstone reservoirs of the Yanchang Formation in the Ordos Basin, which is located in northwest China. The location and distribution of the studied tight sandstone are displayed in Figure 1. During the early Paleozoic, the Ordos Basin evolved from the continental margin ocean basin to the coastal shallow ocean basin, the inland basin, and the foreland basin and finally formed a basin pattern with complete stratigraphic structure and simple structure. In the Late Triassic, the Ordos Basin stretched and subsided, forming a large freshwater lake inside the basin and depositing a set of terrigenous clastic rock series dominated by fluvial-lacustrine facies, which is the Yanchang Formation. The Yanchang Formation is characterized by a fluvial-lacustrine facies sedimentary system formed during the continuous depression and stable sedimentation in the Ordos Basin, which experienced the whole process of generation, expandation, evolution, and subduction. According to the characteristics of the reservoirs, the Yanchang Formation can be divided into 10 sections. Chang 8 and Chang 6 are the main oil-bearing layers with relatively stable distribution and good oil-bearing properties. The buried depth of the Yanchang Formation in the study area is between 1650 and $2150 \mathrm{~m}$ with multiple overlapped oil layers. The distribution of oil layers is scattered, and the argillaceous and calcareous interlayer is relatively developed with different thicknesses and shielding conditions.

According to the general requirements of the rock mechanical test, cylindrical core samples were prepared with a diameter of $25 \mathrm{~mm}$ and a height of $50 \mathrm{~mm}$. The porosity and permeability of the cores are low. Due to the limitations of coring costs and core quality, only three core samples were selected for testing for each well depth. The porosity and permeability were determined by the Core Measurement System (CM300, USA). The measurement ranges of porosity and permeability are $0.01-40 \%$ and $0.00005-15 \mathrm{D}$, respectively. The device is composed of an ISCO pump, vacuum pump, confining pressure pump, core holder, transfer containers, flow meters, nitrogen bottle, and thermostat. The specific experiment method porosity and permeability are measured according to the industrial standard SY/T 5336-2006Practices for Core Analysis. The contents of minerals in the core were measured with the X-ray diffractometer (XRD-6000, Japan). The measurement method followed 


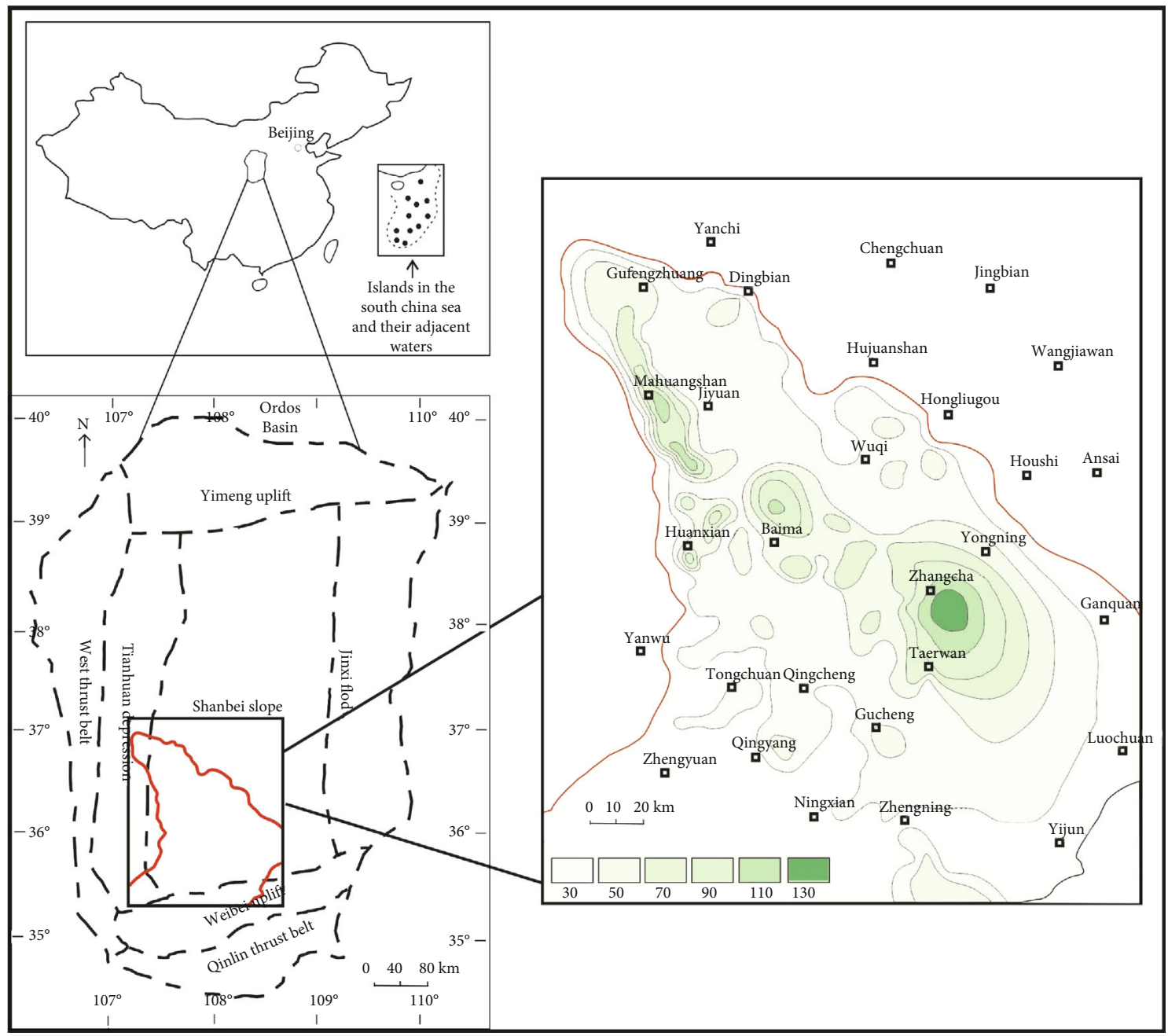

FIGURE 1: Location of the Ordos Basin and isopach map of the Yanchang Formation (contour intervals in meters).

the industrial standard SY/T 5163-2010-Analysis Method for Clay Minerals and Ordinary Non-Clay Minerals in Sedimentary Rocks by the X-Ray Diffraction. Table 1 summarizes the physical properties and mineral compositions of the studied tight sandstones.

The cores used in this study were taken from the Chang 7 Member of the Yanchang Formation. The green contour line in Figure 1 shows the thickness contour and sedimentary facies of the Chang 7 tight sandstone, which has the characteristics of large-scale distribution, good lateral continuity, and large thickness variation. The maximum thickness is $130 \mathrm{~m}$, and the average thickness is above $10 \mathrm{~m}$.

The X-ray diffraction analysis indicates that types of clay minerals in the studied area are mainly kaolinite, chlorite, illite, and mixed illite/smectite, and their contents are $17.0 \%, 41.3 \%, 21.3 \%$, and $20.4 \%$, respectively. The occurrence characteristics of clay minerals are analyzed and verified by SEM, and results are shown in Figure 2.

To avoid the impact of laboratory water on the microscopic pore throat structure of tight sandstone during water cooling and core flooding (for NMR measurement), the synthetic formation water from the target reservoir was used in the experiments (the water type is $\mathrm{CaCl}_{2}$, and salinity is approximately $18000 \mathrm{mg} / \mathrm{L}$; the viscosity and density at $50^{\circ} \mathrm{C}$ are $0.521 \mathrm{mPa} \cdot \mathrm{s}$ and $1.02 \mathrm{~g} / \mathrm{cm}^{3}$, respectively [26]).

2.2. Experimental Setups. In the experiments, a servo control rock mechanics triaxial experimental system (Model TAW1000) was applied for the uniaxial compression test. This system was equipped with the Germany DOLI company's EDC full-digital servo control. The wave velocity test was performed using the Panamerics Model 5058PR high voltage pulse-receiver; the longitudinal wave velocity was measured by the Vaseline coupling test. The SXW-1200 hightemperature box-type resistance furnace (manufactured by the Shanghai Shiyan Electric Furnace Co., Ltd., China, with the highest stability of up to $1200^{\circ} \mathrm{C}$ ) was adopted for the high-temperature heat treatment of tight sandstones.

The nuclear magnetic resonance (NMR) setup (manufactured by the Niumag Corporation, China) was used to measure the $T_{2}$ spectrum of synthetic formation water under various experimental conditions. The NMR instrument is comprised of a magnetic body, a radio frequency emitter, and a data collection system. The basic parameters for 
Table 1: Properties and mineral compositions of the studied tight sandstone core samples.

\begin{tabular}{lccccccc}
\hline \multirow{2}{*}{ Sample no. } & \multirow{2}{*}{ Porosity $(\%)$} & \multirow{2}{*}{ Permeability $(\mathrm{mD})$} & Density $\left(\mathrm{g} / \mathrm{cm}^{3}\right)$ & \multicolumn{4}{c}{ Type and content (\%) of mineral } \\
Quartz & Feldspar & Carbonate & Total content of clay minerals \\
\hline H27-1 & 6.52 & 0.10 & 2.43 & 64.9 & 15.6 & 3.1 & 16.4 \\
H27-2 & 6.76 & 0.12 & 2.42 & 59.7 & 18.4 & 4.4 & 17.5 \\
H27-3 & 6.61 & 0.11 & 2.43 & 61.7 & 17.5 & 4.2 & 16.6 \\
H28-1 & 6.98 & 0.15 & 2.58 & 60.2 & 16.8 & 10.7 & 12.3 \\
H28-2 & 7.10 & 0.16 & 2.58 & 62.1 & 16.2 & 9.8 & 11.9 \\
H28-3 & 7.08 & 0.16 & 2.57 & 61.4 & 16.4 & 9.5 & 12.7 \\
H29-1 & 5.90 & 0.06 & 2.52 & 60.4 & 20.3 & 4.0 & 15.3 \\
H29-2 & 6.31 & 0.07 & 2.53 & 61.5 & 21.5 & 3.5 & 13.5 \\
H29-3 & 6.42 & 0.08 & 2.51 & 60.3 & 22.1 & 3.1 & 14.5 \\
H30-1 & 9.11 & 0.21 & 2.50 & 52.7 & 20.9 & 12.0 & 14.0 \\
H30-2 & 8.41 & 0.18 & 2.49 & 50.4 & 22.3 & 13.3 & 14.8 \\
H30-3 & 9.03 & 0.19 & 2.50 & 50.5 & 22.3 & 12.4 & \\
\hline
\end{tabular}

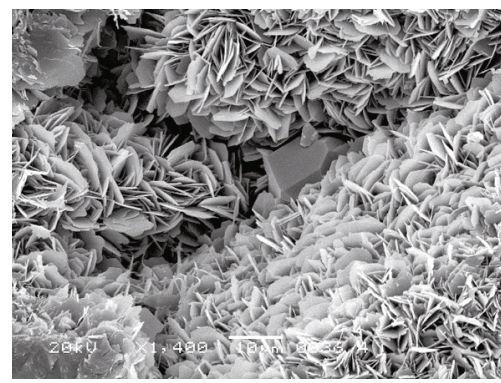

(a) H27, $2054.70 \mathrm{~m}$, chlorite

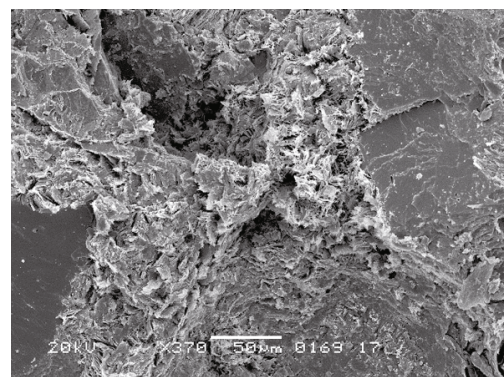

(c) H29, $2073.20 \mathrm{~m}$, illite

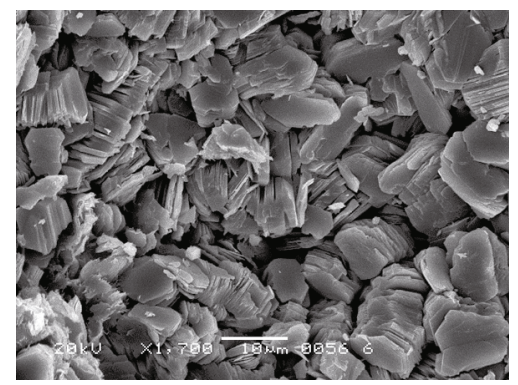

(b) H28, $1934.50 \mathrm{~m}$, kaolinite

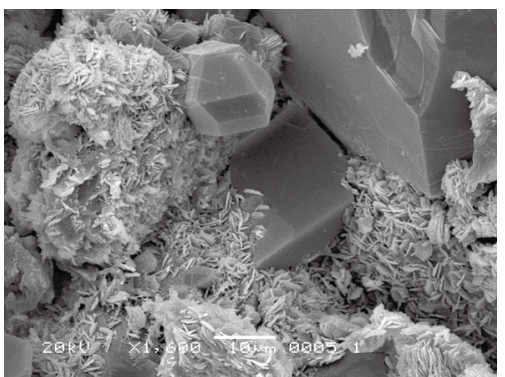

(d) H30, 2016.46 m, Needle-leaf chlorite

Figure 2: The occurrence characteristics of clay minerals of the Yanchang Formation in the Ordos Basin.

NMR measurements are configured with the waiting time of $5 \mathrm{~s}$, the echo time of $0.25 \mathrm{~ms}$, the scanning number of 16 , and the echo number of 1024 .

The NMR technique is a nondestructive detection method. The $T_{2}$ spectrum of the core sample saturated with single-phase fluid can reflect the internal pore structure of the core. In a uniform magnetic field, the transverse relaxation time $T_{2}$ is expressed as

$$
\frac{1}{T_{2}}=\frac{1}{T_{2 B}}+\frac{1}{T_{2 S}}=\frac{1}{T_{2 B}}+\rho \frac{S}{V},
$$

where $\rho$ is the relaxation rate $(\mu \mathrm{m} / \mathrm{ms})$ and $S / V$ is the specific surface area $(1 / \mu \mathrm{m})$.
Since $T_{2 B}$ is far greater than $T_{2}, 1 / T_{2 B}$ can be neglected (i.e., the $T_{2}$ relaxation contribution is mainly from surface relaxation). The following is given:

$$
\frac{S}{V}=\frac{F_{S}}{r_{c}}
$$

where $F_{S}$ is the shaper factor of the single pore $\left(F_{S}=3\right.$ for spherical pore and $F_{S}=2$ for cylindrical pore) and $r_{c}$ is the pore radius $(\mu \mathrm{m})$.

By replacing Equation (2), Equation (1) can be rewritten as

$$
T_{2}=\frac{r_{c}}{\rho F_{S}}
$$


Assuming $C=\rho F_{S}$, Equation (3) can be transformed to

$$
T_{2}=\frac{1}{C} \cdot r_{c}
$$

As seen from Equation (4), the transverse relaxation time $T_{2}$ is in a positive linear relationship with the pore radius $r_{c}$. Thus, the measurement of hydrogen signals can be used to calculate the fluid distribution in different pores.

2.3. Experimental Procedures. Four groups of cores (H27, $\mathrm{H} 28, \mathrm{H} 29$, and H30) taken from the same well depth were selected for experiments. The physical properties of each core were measured at $25^{\circ} \mathrm{C}$ (i.e., the normal temperature). Each group had three core samples: two of them were treated separately at $200,400,600$, and $800^{\circ} \mathrm{C}$, and another sample was chosen as the blank case for comparison. The experimental objective was to simulate the stimulation process of a tight sandstone reservoir using high-energy gas or explosive fracturing followed by hydraulic fracturing and analyze the microscopic pore structure and mechanical properties of tight sandstone after water cooling and natural cooling. The experimental procedures were summarized as follows:

(1) Core sample was put in an extraction container and flushed with benzene and alcohol with a volume ratio of $1: 3$ to remove residual oil. After that, the core was placed in a thermostat and heated to a formation temperature of $50^{\circ} \mathrm{C}$; the temperature was remained unchanged for $48 \mathrm{~h}$. Then the core was taken out to measure the weight, dimensions, and gas permeability

(2) Given that the pore throat radius of tight sandstone was small and the conventional vacuum saturation was unable to fully saturate the pores of the core with water, the core sample was placed in a core holder and flushed with synthetic formation water using a high-pressure displacement device. When the produced liquid was about $5 \mathrm{PV}$, the core was considered fully saturated and the $T_{2}$ spectrum was measured for the first time. After that, the synthetic formation water-saturated core was centrifuged by a PC-12B centrifuge (the rotational speed was set at $11000 \mathrm{r} / \mathrm{min}$ ), and the $T_{2}$ spectrum was measured again, as well as the permeability and longitudinal wave velocity of the core

(3) After centrifugation, two cores chosen from the same group were heated at a rate of $5^{\circ} \mathrm{C} / \mathrm{min}$. After reaching the set temperature, it was kept for $2 \mathrm{~h}$. Then the cores were taken out and cooled by two methods, i.e., natural cooling and synthetic formation water cooling. After cooling, step (2) was repeated, and the $T_{2}$ spectrum and longitudinal wave velocity of the core were measured

(4) At last, the uniaxial compression experiment was performed for the core sample with a loading speed of $0.02 \mathrm{~mm} / \mathrm{min}$ to obtain the stress-strain curve

\section{Results and Discussion}

\subsection{Effect of High-Temperature Heat Treatment on Physical Properties of Tight Sandstone}

3.1.1. Variation of Acoustic Wave Velocity. When an acoustic wave passes through different media, wave velocity varies. If there are cracks, cavities, or other defects inside the media, the acoustic wave velocity decreases. The wave velocity reflects the matrix integrity and fracture development of the rock. Due to the limited core samples, the normalization method has been applied to exclude the influences of physical properties and mineral compositions of different core samples on acoustic wave velocity:

$$
a=\frac{S_{i}}{S_{o}} \times 100 \% \text {, }
$$

where $a$ is the variation of acoustic wave velocity, dimensionless, and $S_{o}$ and $S_{i}$ are the acoustic wave velocities of the core before and after heat treatment, respectively $(\mathrm{m} / \mathrm{s})$.

Figure 3 displays variations of relative wave velocity of core samples with temperature under different cooling methods. It is observed that the declining amplitude of wave velocity increases with temperature in the range of $25-800^{\circ} \mathrm{C}$. This is because core samples undergo heating and cooling processes in the experiments. On the one hand, the degree of damage in the core caused by heat treatment exacerbates with the increment of temperature. On the other hand, the temperature increase consequentially brings about a temperature difference between the core and cooling fluid, intensifying the effect of cold shock and aggravating the cooling-induced damage [27]. These two factors contribute to the decrease of wave velocity. At $600^{\circ} \mathrm{C}$, the wave velocity falls off markedly. In addition to thermal damage, it is also attributed to the enlarged pores and newly formed microcracks that are caused by the physicochemical changes of some minerals due to heat adsorption during the high-temperature heat treatment. For instance, as indicated in Table 1, the tight sandstone contains a high content of quartz (the minimum content is greater than $50 \%$ ). At $573^{\circ} \mathrm{C}$, the transition from $\alpha$ -type to $\beta$-type quartz takes place. When the temperature exceeds $400^{\circ} \mathrm{C}$, the magnesium-illite and kaolinite begin decomposition; when the temperature is beyond $500^{\circ} \mathrm{C}$, the dolomite, magnesium carbonate, and calcium montmorillonite decompose $[19,28,29]$. The physicochemical changes of these minerals significantly alter the microscopic pore structure of the core, increase the core volume, and further give rise to a certain degree of spalling and fragmentation.

In the range of $25-800^{\circ} \mathrm{C}$, comparing wave velocity changes under two different cooling methods indicates that the declining amplitude of wave velocity of the core under synthetic formation cooling is $1.31 \%-10.12 \%$ higher than that of the natural cooling. The possible reason for this phenomenon can be explained that the surface temperature of the core has a sharp decline during the water cooling; hence, a higher temperature gradient is formed inside the core, which brings about the secondary thermal stress, causes 


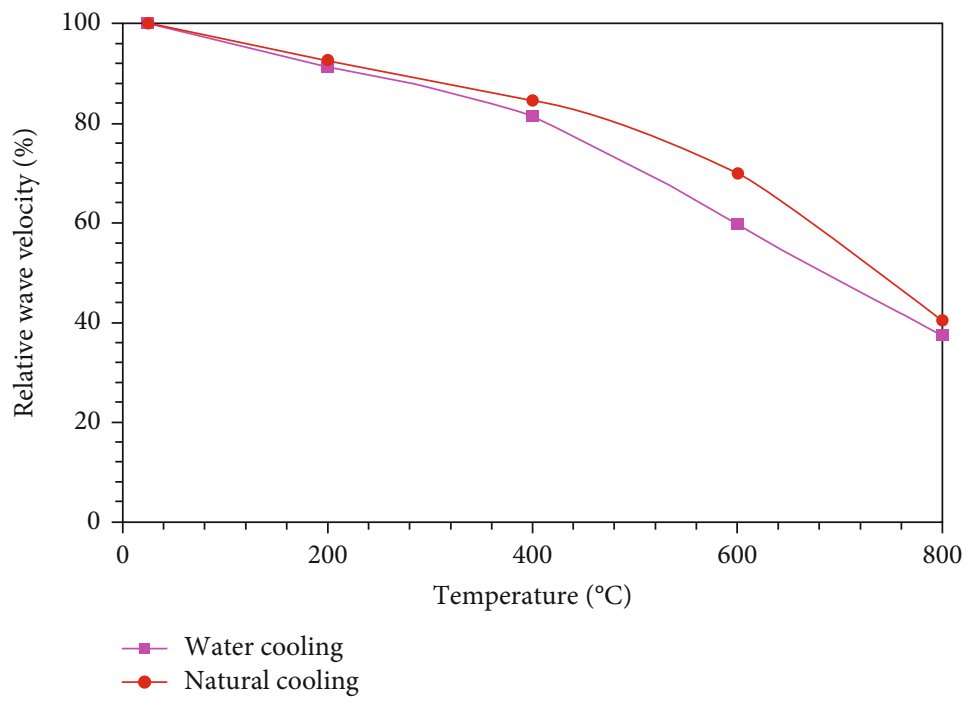

Figure 3: The variations of relative wave velocity of core samples with temperature under two different cooling methods.

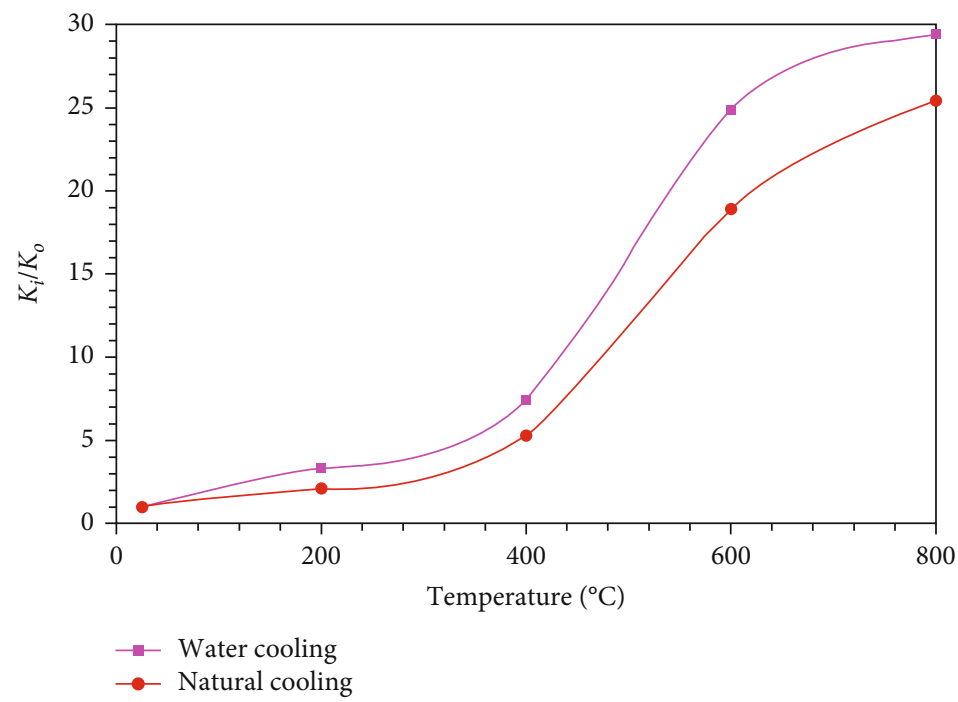

FIGURE 4: The variations of permeability of core samples with temperature under two different cooling methods.

greater thermal damage, and accelerates the deterioration of tight sandstone.

3.1.2. Variation of Permeability. Permeability change can be used as an indicator to evaluate the degree of damage to the core and the improvement of its physical properties under the high-temperature heat treatment intuitively and quantitatively. Figure 4 compares the permeability change of core samples under synthetic formation water cooling and natural cooling at $25-800^{\circ} \mathrm{C}$ (where $K_{o}$ and $K_{i}$ are the permeabilities of the core before and after heat treatment, respectively). It is noted that, under both cooling methods, the increasing amplitude of permeability of the core goes up with temperature and there is a sudden change in permeability, implying the existence of threshold temperature (i.e., the temperature at which the physical properties of the core alter drastically). Around the threshold temperature, the core's permeability undergoes a sudden change; below it, the permeability increases slightly with temperature; above it, the permeability increases rapidly with temperature. Accordingly, the results from this figure imply that the threshold temperature of the studied tight sandstone is between $400^{\circ} \mathrm{C}$ and $600^{\circ} \mathrm{C}$. In this range, the permeability of tight sandstone alters by orders of magnitude, signifying that the internal structure of tight sandstone has changed significantly. This change is consistent with the variation of acoustic wave velocity, which can be attributed to the chemical decomposition of some minerals (e.g., magnesium illite, kaolinite, dolomite, magnesium carbonate, and calcium montmorillonite), the phase transition of some minerals (e.g., quartz), or the oxidation of some rocks (such as siderite and pyrite).

Based on the permeability variations of core samples under two different cooling methods, it is found that the permeability of the synthetic formation water-cooled core is increased by 3.34-29.45 times and that of the naturally cooled core is risen by $2.08-25.45$ times at $25-800^{\circ} \mathrm{C}$. Considering 


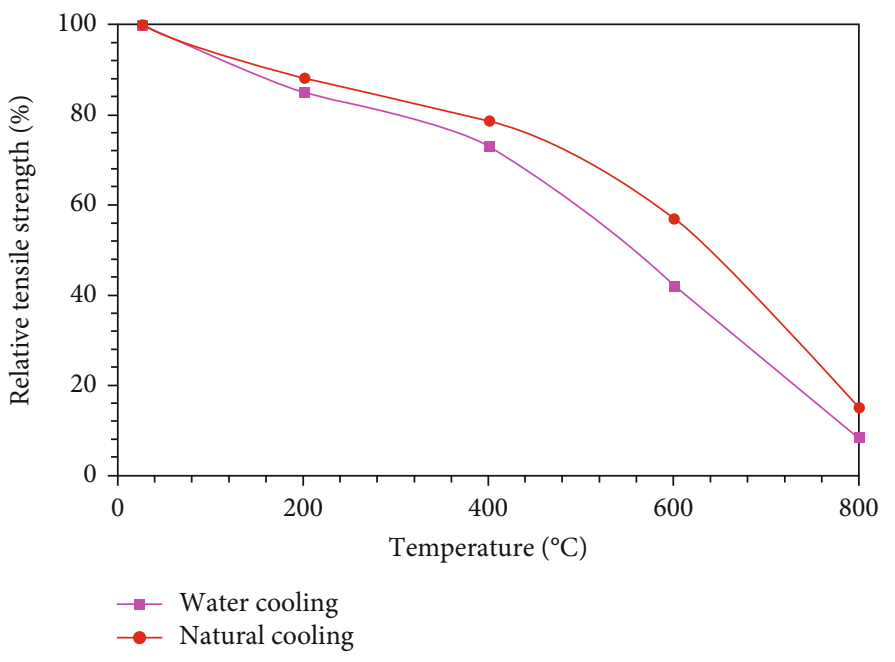

Figure 5: The variations of the tensile strength of core samples with temperature under two different cooling modes.

thermal damages are almost the same at the identical temperature under these two cooling methods, the effect of heating is negligible. For the cores at the same temperature, the effect of water cooling on the enhancement of permeability is more significant than that of natural cooling. This is because, compared to natural cooling, the temperature difference between synthetic formation water and hightemperature core is greater, leading to a stronger cold shock and the propagation of original cracks in the core. This, in turn, results in a higher increasing amplitude of permeability under the water cooling.

As plotted in Figures 3 and 4, the biggest differences in acoustic wave velocity and permeability emerge at $600^{\circ} \mathrm{C}$, but the differences become smaller at $800^{\circ} \mathrm{C}$. The reason is that the synthetic formation water cooling causes a more dramatic surface temperature drop of the core at $600^{\circ} \mathrm{C}$, resulting in a larger temperature gradient and greater thermal damage which aggravates the degradation of the core. However, at $800^{\circ} \mathrm{C}$, the minerals in tight sandstone are fully expanded after high-temperature heat treatment. A large number of micropores are formed, and the preexisting pores are further enlarged and connected, which weaken the mechanical properties of the core. Although the water cooling could further degrade mechanical properties, the effect is not significant and thus the differences between these two cooling methods are not obvious at $800^{\circ} \mathrm{C}$.

\subsection{Effect of High-Temperature Treatment on Rock Mechanical Properties of Tight Sandstone}

3.2.1. Variation of Tensile Strength. Authors [30] have carried out a series of the Brazilian splitting tests and longitudinal wave velocity tests in tight sandstones of the Yanchang Formation in the Ordos Basin and established a tensile strength prediction model for tight sandstone in terms of the longitudinal wave velocity and density. The correlation coefficient of the model is greater than 0.93 , and the maximum error is within $5 \%$ as compared to the measured field data.

$$
\sigma_{t}=a \ln \left(V_{p}\right)+b \cdot \rho-c,
$$

where $\sigma_{t}$ is the uniaxial tensile strength $(\mathrm{MPa}) ; V_{P}$ is the longitudinal wave velocity $(\mathrm{m} / \mathrm{s}) ; \rho$ is the rock density $\left(\mathrm{g} / \mathrm{cm}^{3}\right)$; and $a, b$, and $c$ are dimensionless coefficients. Considering the effect of heat-induced microcracks on wave velocity, the recommended values for coefficients $a, b$, and $c$ are 16.69 , 9.36 , and 136.12 , respectively.

After the high-temperature heat treatment, the dimensions of the core at each temperature were measured. Experimental results show that the diameter of the core is slightly reduced, its length is enlarged somewhat, and its total volume is increased. Accordingly, the density of the core is slightly increased with temperature.

Due to the limited number of core samples in this study, the tensile strengths of tight sandstone samples after hightemperature heat treatment were analyzed by adopting the above model (Equation (6)). Likewise, the normalization method was applied to eliminate the effects of physical properties and densities of different rocks on tensile strength.

Figure 5 presents the comparison of the tensile strength of core samples under two different cooling methods. With the rise of temperature, the tensile strength of the core after being cooled exhibits a decreasing trend, indicating that the damage caused by heating and cooling the core reduces the tensile strength. The declining amplitude of tensile strength enlarges with the increase of heating temperature. Comparing Figures 3 and 5 indicates that the declining amplitude of tensile strength is greater than that of the acoustic wave velocity, signifying that the propagation of cracks in the tight sandstone after the heating and cooling treatments reduces wave velocity and density of the core concurrently.

The tensile strengths of the core treated by synthetic formation water cooling are $2.97 \%$ and $5.61 \%$ lower than that of the core under the natural cooling at $200^{\circ} \mathrm{C}$ and $400^{\circ} \mathrm{C}$, respectively. It indicates that the effect of different cooling methods on the tensile strength is not significant in this temperature range. At $600^{\circ} \mathrm{C}$, compared to the natural cooling, the tensile strength of the core under the water cooling is $14.21 \%$ lower. In addition, the density change is taken into account. The densities of the cores after the water cooling and natural cooling are $2.45 \mathrm{~g} / \mathrm{cm}^{3}$ and $2.47 \mathrm{~g} / \mathrm{cm}^{3}$, respectively, which 
are slightly decreased as compared to the densities of the cores before heat treatment $\left(2.53 \mathrm{~g} / \mathrm{cm}^{3}\right.$ and $2.51 \mathrm{~g} / \mathrm{cm}^{3}$, respectively). By combining these findings, it can be concluded that water cooling has a greater impact on the tensile strength of tight sandstone than natural cooling. This is because the water cooling can promote the propagation of original cracks in the core and aggravate the degree of thermal damage to the core. The higher the chance of water cooling-induced crack propagation and connectivity, the more severe the thermal damage.

3.2.2. Stress-Strain Characteristics. The stress-strain curves of tight sandstones after synthetic formation water cooling and natural cooling are plotted in Figures 6 and 7. After hightemperature heat treatment and under the uniaxial compression test, it is found that the stress-strain curve of the core samples generally includes four stages, i.e., densification, elasticity, yielding, and failure. With increasing temperature, the peak stress of the water-cooled tight sandstone shows a trend of first rising and then declining, same as the change in axial strain. In comparison with natural cooling, the peak stress of the core after water cooling is lower at each temperature and the stress drops rapidly after reaching the peak of the stress-strain curve, presenting certain brittle failure characteristics.

As indicated in these two figures, when the heating temperature is below $600^{\circ} \mathrm{C}$, the densification stage is not noticeable in the stress-strain curve of tight sandstone after water cooling and natural cooling. As the temperature continues to rise, the densification stage emerges. The reason for this phenomenon is that when the temperature is not high, the thermal expansion coefficients of different minerals lead to a small extent of uneven thermal expansion and deformation between mineral particles. The consequent result is to cause thermal deformation of some fine sandstone particles, promote the gradual closure of some original microcracks, and improve the compactness of the core. As the temperature goes up, the uneven expansion between mineral particles becomes more pronounced. When the resulting thermal stress exceeds the tensile strength of the core, new cracks are induced and the number of microcracks climbs. Besides, the effusion of crystal water from the mineral destroys the crystal lattice structure of the mineral, resulting in increased internal cracks and enhanced connectivity and thus exhibiting a more obvious densification stage.

3.2.3. Variations of Peak Strength and Elastic Modulus. The peak strength of the core can directly reflect its ability to resist compression failure. Figure 8 compares the peak strengths of core samples under two cooling methods. The peak strengths of tight sandstones treated by synthetic formation water cooling and natural cooling increase first and then decrease sharply. For water cooling, the peak strength reaches the maximum at $200^{\circ} \mathrm{C}$ and decreases significantly when the temperature drops down to $600^{\circ} \mathrm{C}$; however, for natural cooling, the peak strength attains the maximum value at $400^{\circ} \mathrm{C}$ and falls thereafter. When the temperature is not high (i.e., below $400^{\circ} \mathrm{C}$ for water cooling and less than $600^{\circ} \mathrm{C}$ for natural cooling), the heat may cause the thermal deformation of some fine sandstone particles, but the

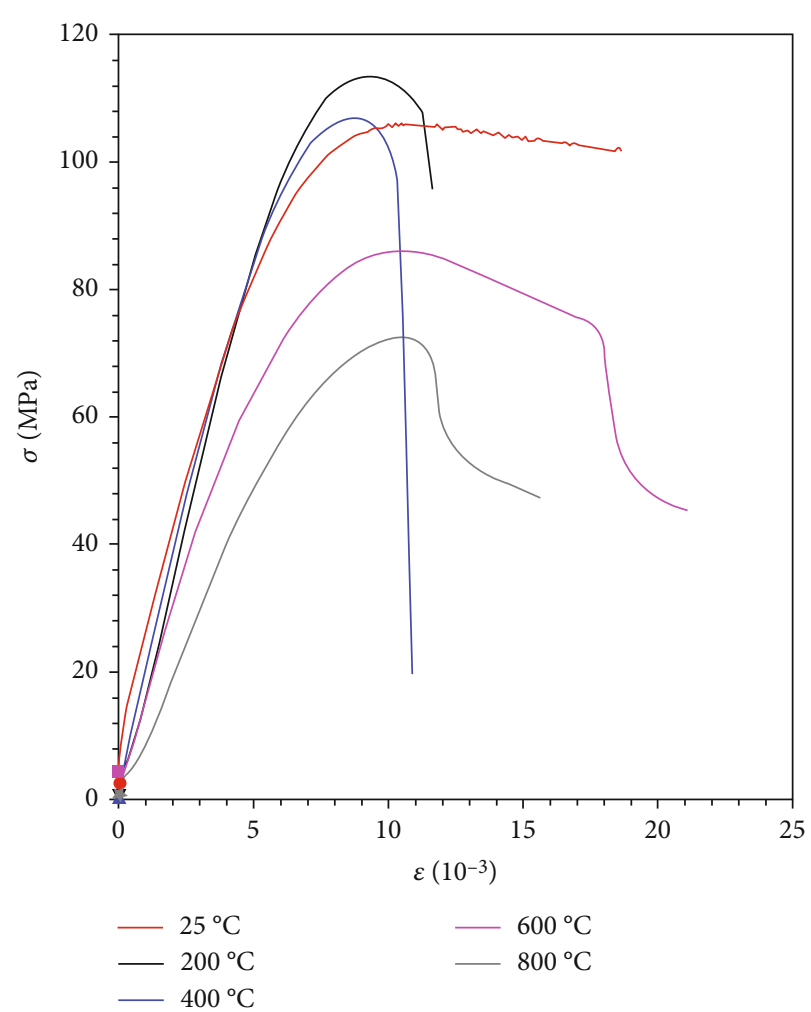

FIgURE 6: Stress-strain curves of tight sandstones after synthetic formation water cooling.

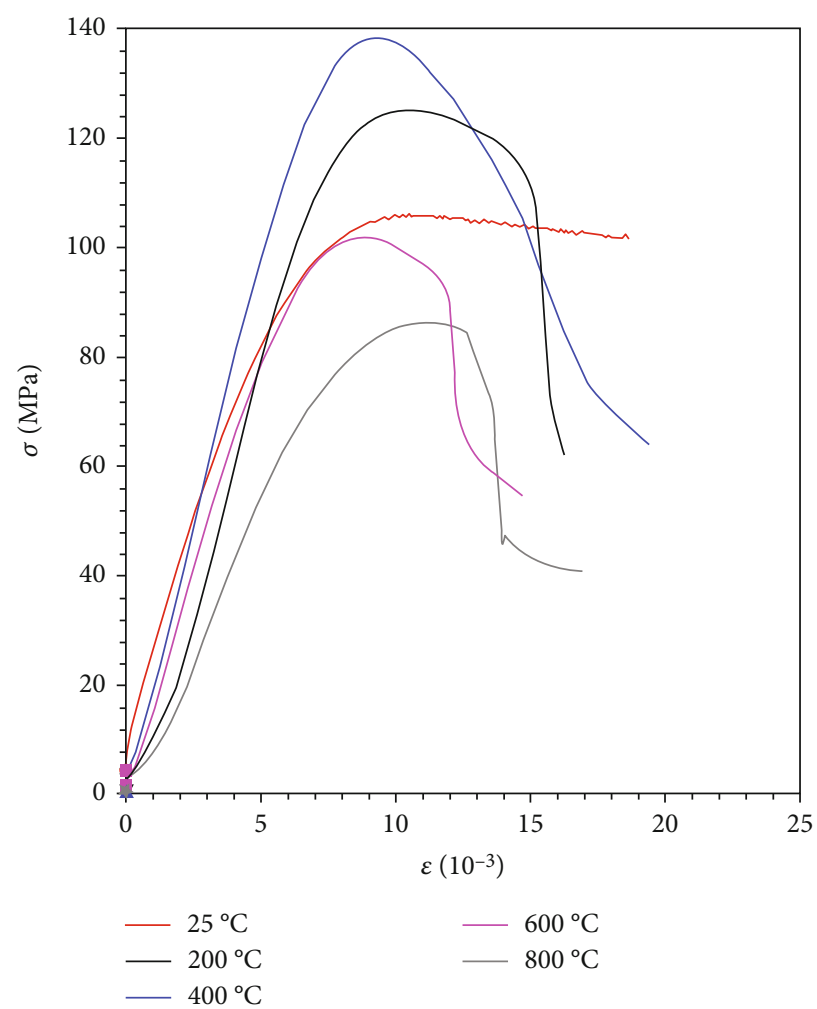

FIgURE 7: Stress-strain curves of tight sandstones after natural cooling. 


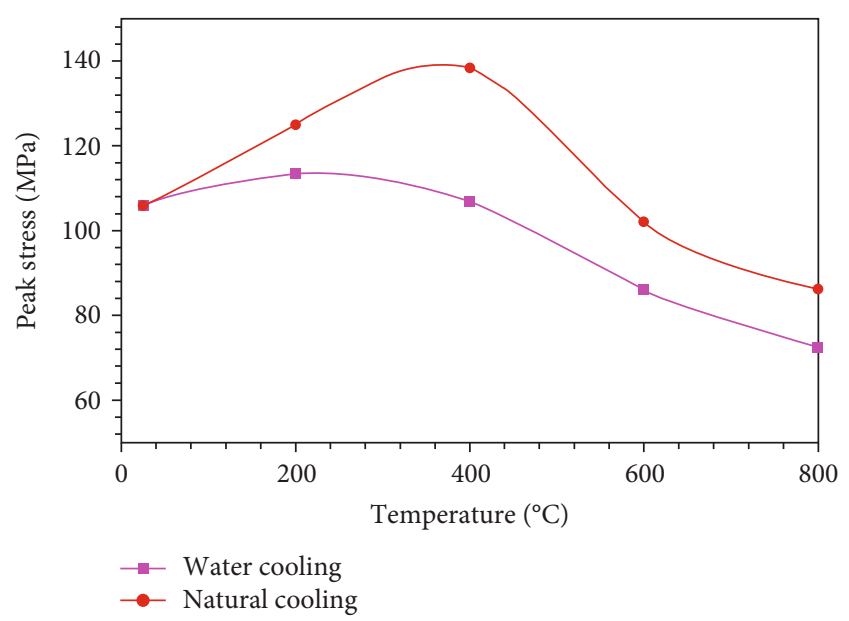

FIgURE 8: The variations of peak stress of core samples with temperature under two different cooling methods.

expansion and deformation of the minerals are small, which promotes the gradual closure of some original microcracks and enhances the compactness and strength of the core. Moreover, the damage caused by cooling after the hightemperature heat treatment is less than the strengthening effect of thermal action on the strength of the core. With the further increment of temperature, the peak strengths of the cores under two cooling methods drop significantly. The peak strength of the water-cooled core is still lower than that of the naturally cooled core, indicating that water cooling has a greater impact on the peak strength of tight sandstone after high-temperature heat treatment than natural cooling.

Figure 9 shows the comparison of elastic modulus of core samples under two different cooling methods, and a resemble trend is observed like the peak strength. At $25-400^{\circ} \mathrm{C}$, the elastic moduli of core samples exhibit an overall increase with temperature. When the cores are heated to $600^{\circ} \mathrm{C}$, the elastic moduli decline. The declining amplitude of elastic modulus of the water-cooled core sample is larger than that of the naturally cooled core, signifying that the significant deterioration has occurred to the mechanical properties of the core. Compared to water cooling, the elastic moduli of the cores under natural cooling are $8.41 \%, 15.32 \%, 34.93 \%$, and $16.59 \%$ higher at four different temperatures (i.e., $25^{\circ} \mathrm{C}$, $200^{\circ} \mathrm{C}, 400^{\circ} \mathrm{C}$, and $600^{\circ} \mathrm{C}$ ), respectively, which demonstrates that the impact of water cooling on the elastic modulus of the core is more obvious than that natural cooling.

\subsection{Effect of High-Temperature Heat Treatment on Pore Structure Characteristics of Tight Sandstone}

3.3.1. Characteristics of NMR $T_{2}$ Spectrum. The $T_{2}$ spectrum and pore size distributions of the tight sandstone samples before and after natural cooling and water cooling at four different temperatures are plotted in Figures 10-13. Before heat treatment, $T_{2}$ values range from 0.1 to $1000.0 \mathrm{~ms}$ and $T_{2}$ spectrums present bimodal distribution. Most of the pore diameters are less than $100.0 \mathrm{~ms}$, indicating that the original core sample mainly contains micropore and mesopores and

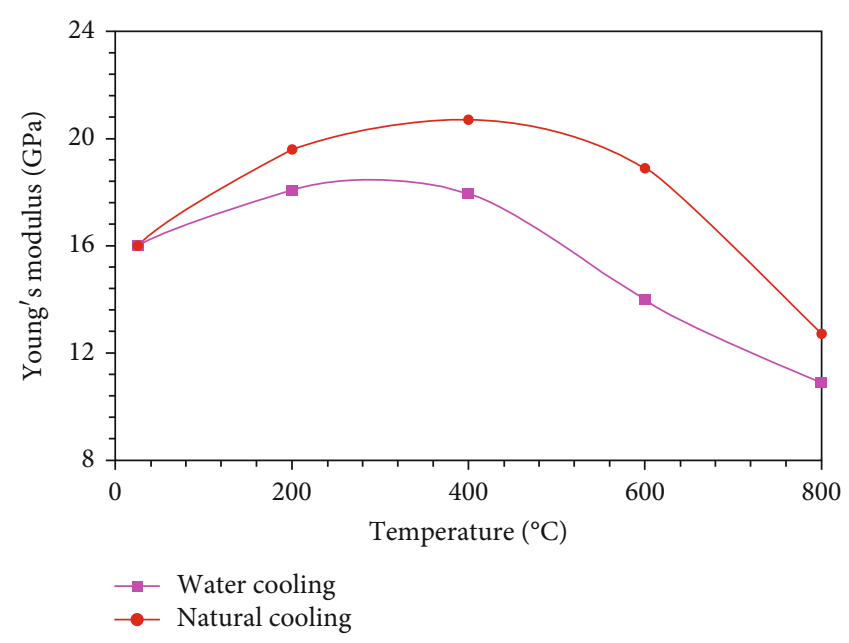

FIgURE 9: The variations of elastic modulus of core samples with temperature under two different cooling methods.

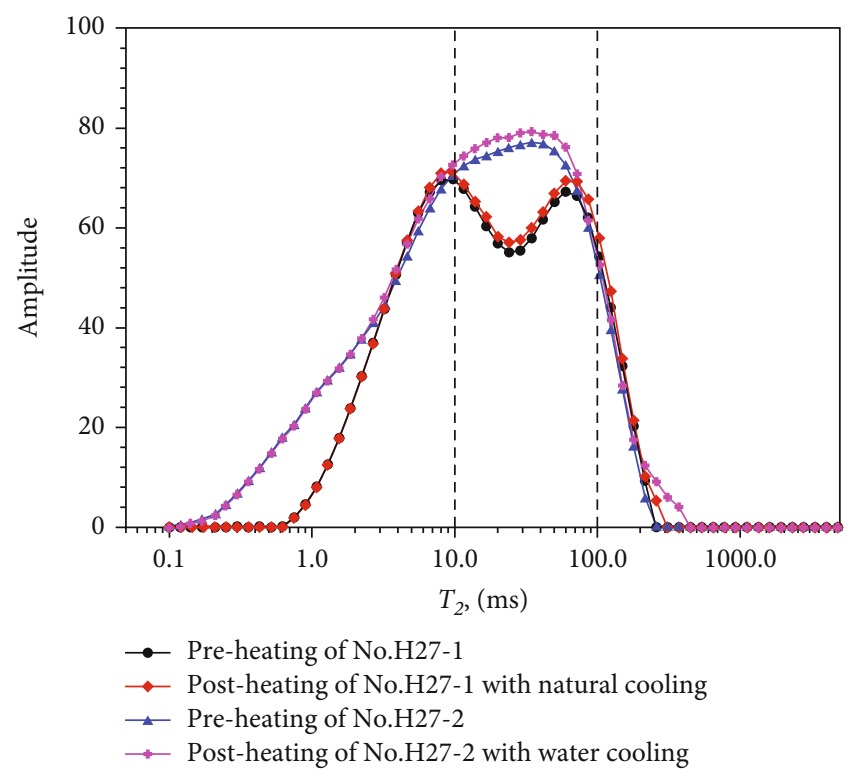

FIgURE 10: $T_{2}$ spectrums and pore size distributions of the core samples (No. H27-1 and No. H27-2) at $200^{\circ} \mathrm{C}$ under two different cooling methods.

has a small number of macropores. After cooling, $T_{2}$ spectrums change significantly with temperature and exhibit bimodal distribution generally. It is noticeable that, under the water cooling, $T_{2}$ spectrums display triple-modal distribution at $600^{\circ} \mathrm{C}$ and $800^{\circ} \mathrm{C}$.

In general, after heat treatment, the area enclosed by the $\mathrm{T}_{2}$ spectrum of the tight sandstone enlarges with the increment of temperature. The synthetic formation water cooling has a larger area of $T_{2}$ spectrum than natural cooling. The number of pores in the core sample before and after cooling follows the sequence: original core sample $<$ natural cooling $<$ water cooling.

3.3.2. Variation of Pore Structure. According to previous studies on tight sandstone $[26,31]$, the pore sizes can be 


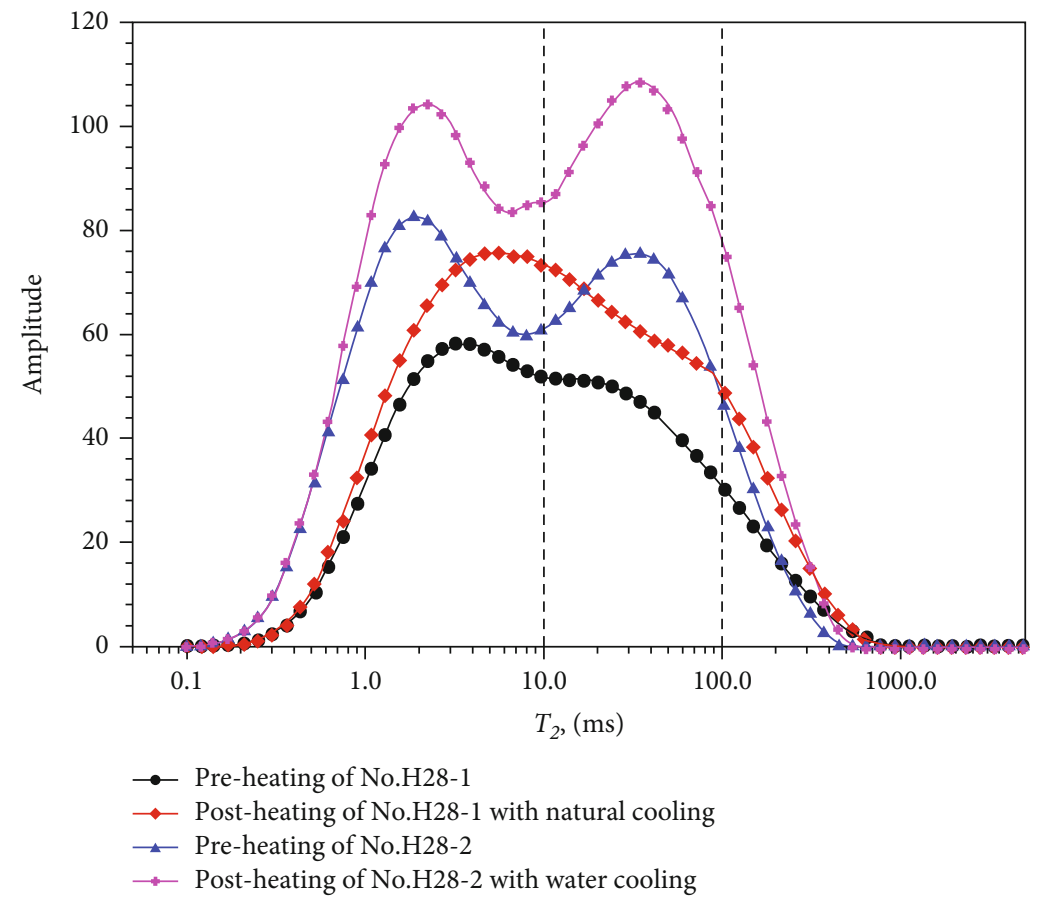

Figure 11: $T_{2}$ spectrums and pore size distribution of the core samples (No. H28-1 and No. H28-2) at $400^{\circ} \mathrm{C}$ under two different cooling methods.

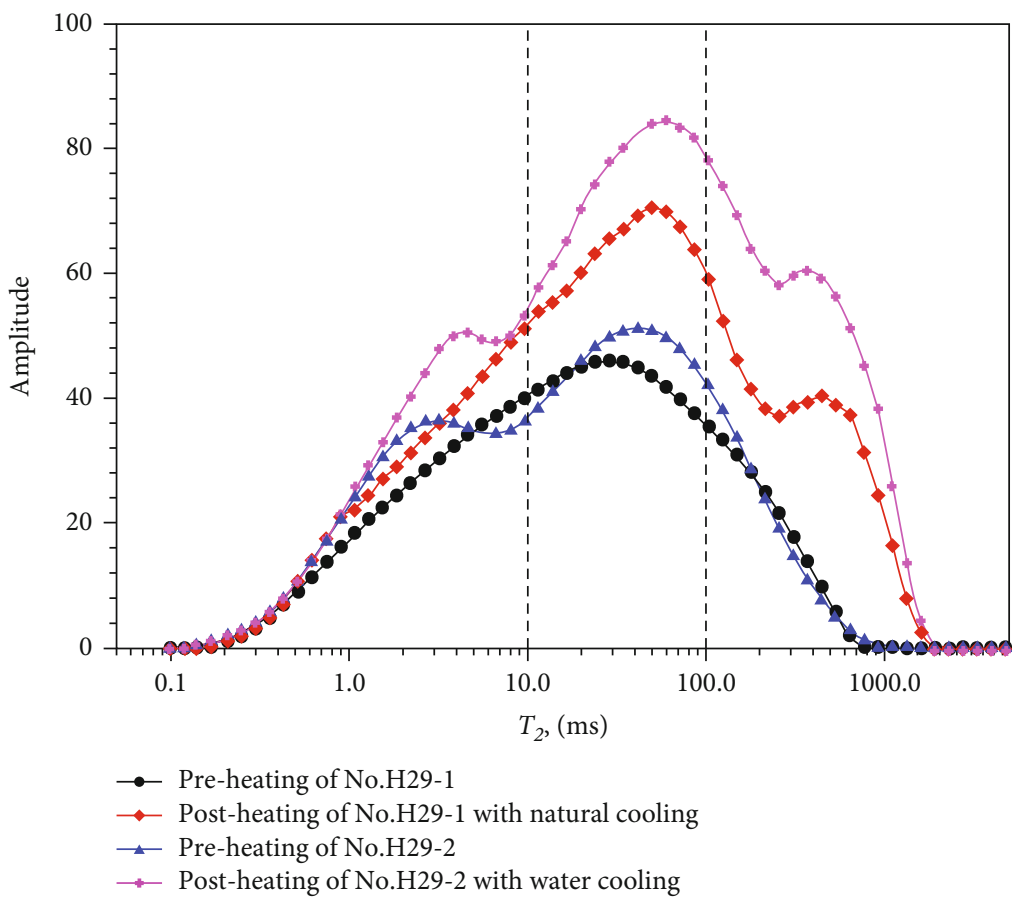

Figure 12: $T_{2}$ spectrums and pore size distribution of the core samples (No. H29-1 and No. H29-2) at $600^{\circ} \mathrm{C}$ under two different cooling methods.

categorized into micropores $(<10.0 \mathrm{~ms})$, mesopores $(10.0 \sim 100.0 \mathrm{~ms})$, and macropores $(>100 \mathrm{~ms})$ in terms of the NMR $T_{2}$ value. As the temperature changes, pores with different sizes exhibit different characteristics. As shown in Figure 14, the number of micropores has little change at different temperatures under two different cooling methods. Yet the number of mesopores goes up with temperature. When the temperature reaches $800^{\circ} \mathrm{C}$, the number of mesopores is risen by 1.92 times under natural cooling and 2.14 times under water cooling. It is worth noting that the number of macropores varies most obviously; especially at $600^{\circ} \mathrm{C}$, there is a sudden increment of the number. At $800^{\circ} \mathrm{C}$, the number 


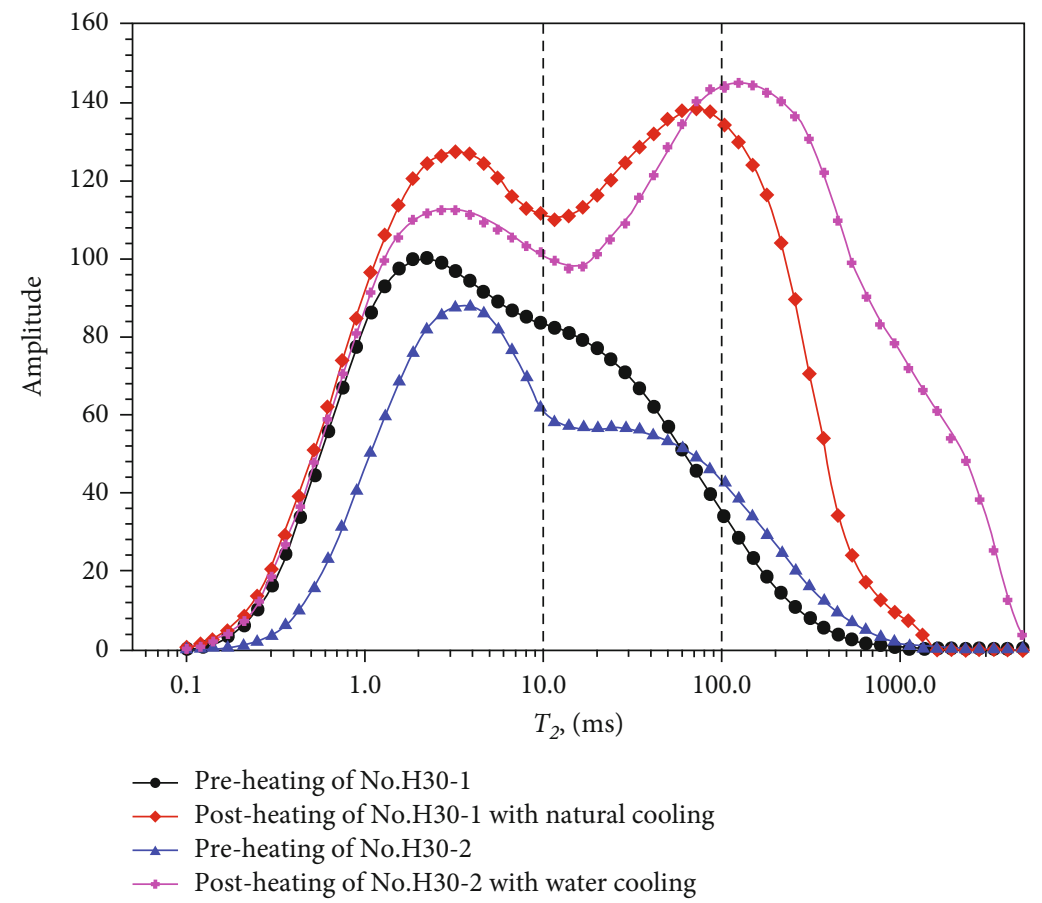

FIGURE 13: $T_{2}$ spectrums and pore size distribution of the core samples (No. H30-1 and No. H30-2) at $800^{\circ} \mathrm{C}$ under two different cooling methods.

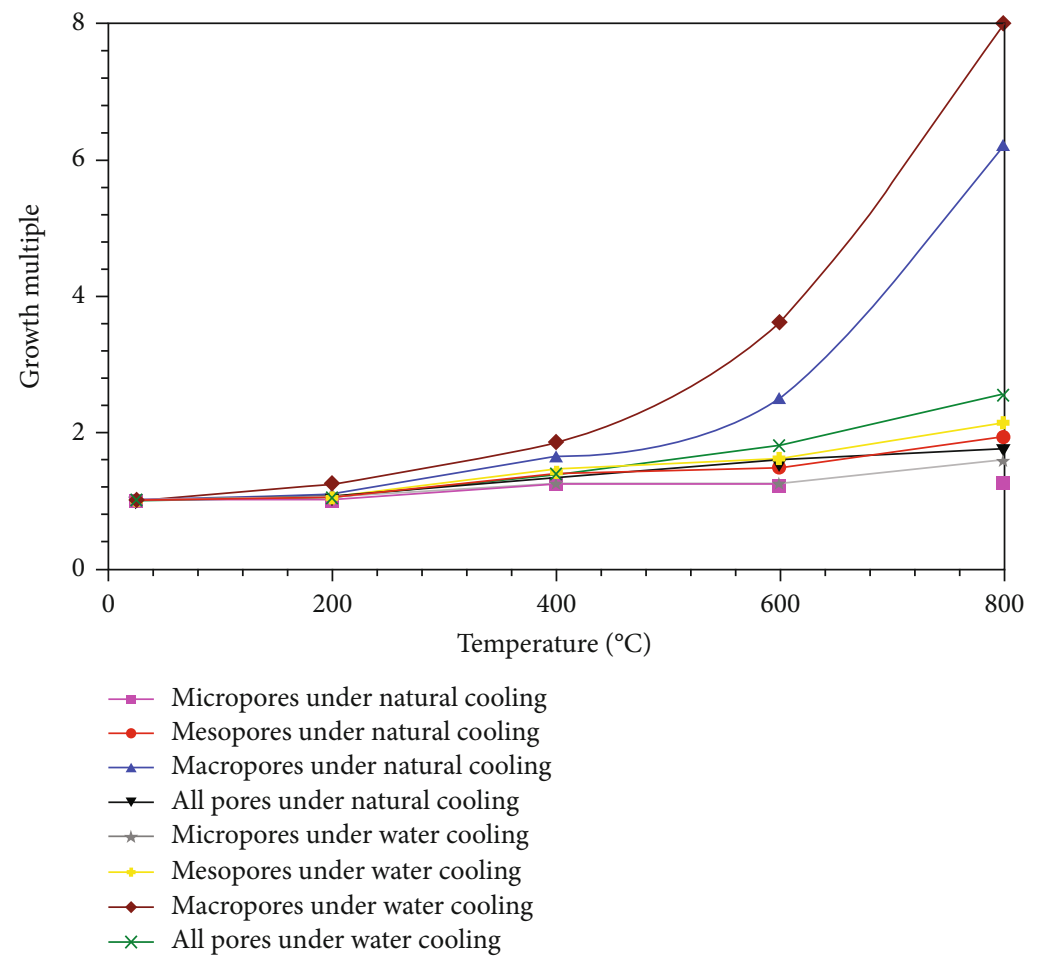

FIGURE 14: Variation of pores in tight sandstone with temperature under two different cooling modes.

of macropores is increased by 6.19 times under natural cooling and 8.00 times under water cooling. The increment amplitude of the overall pore volume is similar to that of the number of mesopores.
At $200^{\circ} \mathrm{C}$, there is no evident change in the number of pores; at $400^{\circ} \mathrm{C}$, the change is still not obvious, except that the number of macropores under water cooling increases. However, at $600^{\circ} \mathrm{C}$, the number of micropores and 
mesopores has a dramatic increase and this trend continues up to $800^{\circ} \mathrm{C}$. When the temperature is at a relatively high value (e.g., $600^{\circ} \mathrm{C}$ or $800^{\circ} \mathrm{C}$ ), the uneven thermal expansion between minerals in the core becomes significant and the ensuing temperature stress can exceed the strength limit of the core, forming more pores than the original core sample. Especially at $800^{\circ} \mathrm{C}$, the pores in the core continue to grow and connect to form large pores and more microcracks, which leads to more severe damage to the core.

For the studied tight sandstone core samples, the variation of pore number measured by the NMR technique resembles the change in mechanical characteristics. This similarity explains to some extent the reason why the mechanical characteristics of tight sandstone alter with temperature. The permeability of the core primarily depends on the mesopores and macropores.

Based on the variations of physical properties, mechanical properties, and microscopic pore structure, the threshold temperature of the tight sandstone is estimated between $400^{\circ} \mathrm{C}$ and $600^{\circ} \mathrm{C}$. Above the threshold temperature, the main characteristics of tight sandstone will change significantly. Another finding from this study is that the cooling method has no obvious impact on the threshold temperature.

In comparison with natural cooling, water cooling can cause greater damage and more dramatic change in the physical properties of the core at a relatively lower temperature. That explains why the threshold temperature under water cooling is slightly lower than that under natural cooling.

\section{Conclusions}

In this paper, a series of tests have been carried out to study the effect of high-temperature heat treatment on the physical properties, mechanical properties, and microscopic pore structure of tight sandstone under synthetic formation water cooling and natural cooling. Based on the experimental results, the following conclusions are obtained:

(1) Compared to natural cooling, the wave velocity of tight sandstone cooled by synthetic formation water is lower, but the permeability of the core is higher. The maximum differences in wave velocity and permeability appear at $600^{\circ} \mathrm{C}$

(2) With the increase of heating temperature, the tensile strength of tight sandstone decreases, and the declining amplitude of tensile strength enlarges. The peak strengths and elastic moduli of the tight sandstone after water cooling or natural cooling show the trend of first rising and then decreasing sharply. Under water cooling, the peak strength and elastic modulus reach the maximum values at $200^{\circ} \mathrm{C}$; under natural cooling, the maximum values are attained at $400^{\circ} \mathrm{C}$. When the core is heated up to $600^{\circ} \mathrm{C}$, both peak strength and elastic modulus fall dramatically

(3) The $T_{2}$ spectrums of tight sandstone change significantly with temperature and generally exhibit bimodal distribution. At $600^{\circ} \mathrm{C}$ and $800^{\circ} \mathrm{C}$ under water cooling, $T_{2}$ spectrums present triple-modal distribution. As the temperature goes up, the number of micropores does not change evidently but the number of mesopores increases. When the temperature reaches $800^{\circ} \mathrm{C}$, the number of mesopores rises 1.92 times under natural cooling and 2.14 times under water cooling. The number of macropores varies most obviously; especially at $600^{\circ} \mathrm{C}$, there is a sudden increment of the number. The pore size and number of pores of the tight sandstone sample after watercooling are higher than those after natural cooling

(4) Based on the variations of physical properties, mechanical properties, and microscopic pore structure of tight sandstone, the threshold temperature is estimated in the range of $400-600^{\circ} \mathrm{C}$. Above the threshold temperature, the main characteristics of tight sandstone will change dramatically

In this paper, the impact of heat treatment time on the physical and mechanical properties of tight sandstone is not addressed (based on previous studies, the treatment time of $2 \mathrm{~h}$ was selected for the experiments). Besides, due to the distinct mineral components of different tight sandstones, the relationship between mineral components of tight sandstone and changes in the microscopic pore structure and mechanical properties of the core during high-temperature heat treatment is not identified. Hence, these problems will be discussed in the next step.

\section{Data Availability}

All data, models, and code generated or used during the study appear in the article, and the authors are not restricted from sharing their data and materials.

\section{Conflicts of Interest}

The authors declare that they have no conflicts of interest.

\section{Acknowledgments}

This research was financially supported by the National Natural Science Foundation of China (Nos. 52074221, 52020105001, and 51974249) and the Foundation of Key Laboratory of Unconventional Oil \& Gas Development (China University of Petroleum (East China)) (No. 19CX05005A-203).

\section{References}

[1] C. Gu, J. Y. Xu, B. X. Meng, M. Wen, and C. X. Lou, "Dynamic mechanical behavior and mesoscopic analysis of two layered sandstone after high temperature," Journal of China Coal Society, vol. 44, no. 9, pp. 2710-2720, 2019.

[2] P. H. Jin, Y. Q. Hu, J. X. Shao, Z. H. Liu, and Y. F. Hu, "Study on pore structure and permeability of granite subjected to heating and water quenching," Journal of Taiyuan University of Technology, vol. 50, no. 4, pp. 478-484, 2019.

[3] J. J. Hu, X. H. Pan, and W. Q. Zhang, "Thermal effect on wave velocity of sandstone after high-temperature treatment: a review," Arabian Journal of Geosciences, vol. 12, no. 22, p. $689,2019$. 
[4] M. Hajpál, "Changes in sandstone of historical monuments exposed to fire or high temperature," Fire Technology, vol. 38, no. 4, pp. 373-382, 2002.

[5] M. Hajpál and A. Török, "Mineralogical and colour changes of quartz sandstones by heat," Environmental Geology, vol. 46, pp. 311-322, 2004.

[6] A. Török and M. Hajpál, "Effect of temperature changes on the mineralogy and physical proper ties of sandstone. A laboratory study," International Journal for Restoration of Buildings and Monuments, vol. 11, no. 4, pp. 1-8, 2005.

[7] H. Tian, T. Kempka, N. X. Xu, and M. Ziegler, "Physical properties of sandstones after high temperature treatment," Rock Mechanics and Rock Engineering, vol. 45, no. 6, pp. 11131117, 2012.

[8] G. Wu, Y. Wang, G. Swift, and J. Chen, "Laboratory investigation of the effects of temperature on the mechanical properties of sandstone," Geotechnical and Geological Engineering, vol. 31, no. 2, pp. 809-816, 2013.

[9] Z. Kompaníková, M. Gomez-Heras, J. Michňová, T. Durmeková, and J. Vlčko, "Sandstone alterations triggered by fire-related temperatures," Environmental Earth Sciences, vol. 72, no. 7, pp. 2569-2581, 2014.

[10] Q. Sun, W. Q. Zhang, T. M. Su, and S. Y. Zhu, "Variation of wave velocity and porosity of sandstone after high temperature heating," Acta Geophysica, vol. 64, no. 3, pp. 633-648, 2016.

[11] X. Liu, S. Yuan, Y. Sieffert, S. Fityus, and O. Buzzi, "Changes in mineralogy, microstructure, compressive strength and intrinsic permeability of two sedimentary rocks subjected to hightemperature heating," Rock Mechanics and Rock Engineering, vol. 49, no. 8, pp. 2985-2998, 2016.

[12] X. Liu, C. Zhang, S. Yuan, S. Fityus, S. W. Sloan, and O. Buzzi, "Effect of high temperature on mineralogy, microstructure, shear stiffness and tensile strength of two Australian mudstones," Rock Mechanics and Rock Engineering, vol. 49, no. 9, pp. 3513-3524, 2016.

[13] N. N. Sirdesai, T. N. Singh, P. G. Ranjith, and R. Singh, "Effect of varied durations of thermal treatment on the tensile strength of red sandstone," Rock Mechanics and Rock Engineering, vol. 50, no. 1, pp. 205-213, 2017.

[14] N. N. Sirdesai, T. N. Singh, and R. P. Gamage, “Thermal alterations in the poro-mechanical characteristic of an Indian sandstone - a comparative study," Engineering Geology, vol. 226, pp. 208-220, 2017.

[15] N. N. Sirdesai, T. Gupta, T. N. Singh, and P. G. Ranjith, "Studying the acoustic emission response of an Indian monumental sandstone under varying temperatures and strains," Construction and Building Materials, vol. 168, pp. 346-361, 2018.

[16] N. N. Sirdesai, A. Singh, L. K. Sharma, R. Singh, and T. N. Singh, "Determination of thermal damage in rock specimen using intelligent techniques," Engineering Geology, vol. 239, pp. 179-194, 2018.

[17] N. N. Sirdesai, B. Mahanta, P. G. Ranjith, and T. N. Singh, "Effects of thermal treatment on physico-morphological properties of Indian fine-grained sandstone," Bulletin of Engineering Geology and the Environment, vol. 78, no. 2, pp. 883-897, 2019.

[18] N. N. Sirdesai, A. Singh, L. K. Sharma, R. Singh, and T. N. Singh, "Development of novel methods to predict the strength properties of thermally treated sandstone using statistical and soft-computing approach," Neural Computing and Applications, vol. 31, no. 7, pp. 2841-2867, 2019.
[19] R. Lei, Y. Wang, L. Zhang et al., "The evolution of sandstone microstructure and mechanical properties with thermal damage," Energy Science \& Engineering, vol. 7, no. 6, pp. 30583075, 2019.

[20] X. Shi, H. Jing, Q. Yin, Z. Zhao, G. Han, and Y. Gao, "Investigation on physical and mechanical properties of bedded sandstone after high-temperature exposure," Bulletin of Engineering Geology and the Environment, vol. 79, no. 5, pp. 2591-2606, 2020.

[21] M. Li, D. Wang, and Z. Shao, "Experimental study on changes of pore structure and mechanical properties of sandstone after high-temperature treatment using nuclear magnetic resonance," Engineering Geology, vol. 275, p. 105739, 2020.

[22] L. X. Xiong and L. J. Yu, "Advances of mechanical properties of rock under high temperature and after high temperature," Journal of Geological Hazards and Environment Preservation, vol. 29, no. 1, pp. 76-82, 2018.

[23] T. Jacobs, "Unconventional resources will require unconventional EOR," Journal of Petroleum Technology, vol. 67, no. 9, pp. 68-70, 2015.

[24] L. Dou, M. Zhang, G. Bi, and T. Li, "Transient flow in wellbores and phase transition ofCO2during formation supercriticalCO2invasion," Energy Science \& Engineering, vol. 7, no. 2, pp. 323-337, 2019.

[25] M. J. Chen, Y. L. Kang, and L. J. You, "Advantages in formation heat treatment to enhance permeability in tight reservoir," Natural Gas Geoscience, vol. 24, no. 6, pp. 1226-1231, 2013.

[26] L. Dou, Y. Xiao, H. Gao, R. Wang, C. Liu, and H. Sun, "The study of enhanced displacement efficiency in tight sandstone from the combination of spontaneous and dynamic imbibition," Journal of Petroleum Science and Engineering, vol. 199, p. 108327, 2021.

[27] Z. W. Huang, H. T. Wen, X. G. Wu et al., "Experimental study on cracking of high temperature granite using liquid nitrogen," Journal of China University of Petroleum (Edition of Natural Science), vol. 43, no. 2, pp. 68-76, 2019.

[28] P. W. J. Glover, P. Baud, M. Darot et al., " $\alpha / \beta$ phase transition in quartz monitored using acoustic emissions," Geophysical Journal International, vol. 120, no. 3, pp. 775-782, 1995.

[29] W. Zhang and C. Lv, "Effects of mineral content on limestone properties with exposure to different temperatures," Journal of Petroleum Science and Engineering, vol. 188, p. 106941, 2020.

[30] K. S. Zhang, M. R. Tang, C. W. Wang, G. T. Wang, L. B. Dou, and H. B. Sun, "Study on prediction method of tensile strength for tight sandstone formation," Progress in Geophysics, vol. 35, no. 4, pp. 1-10, 2020.

[31] H. Gao, C. Wang, J. Cao, M. He, and L. Dou, "Quantitative study on the stress sensitivity of pores in tight sandstone reservoirs of Ordos basin using NMR technique," Journal of Petroleum Science and Engineering, vol. 172, pp. 401-410, 2019. 